\title{
Ragam Jamur Asal Serasah dan Tanah di Taman Nasional Ujung Kulon Indonesia
}

\section{Biodiversity of Mushroom from Litter and Soil in Ujung Kulon National Park, Indonesia}

\author{
IVAN PERMANA PUTRA*, ERA MARDIYAH, NELLY SAIDAH AMALIA, ARIEH MOUNTARA \\ Departemen Biologi, Fakultas Matematika dan Ilmu Pengetahuan Alam, Institut Pertanian Bogor, Bogor 16680, \\ Indonesia
}

Diterima 10 Mei 2017 /Disetujui 18 Juli 2017

\begin{abstract}
Biodiversity is an important aspect which supports life systems on earth as well as maintains ecosystem sustainability and evolution. Fungal communities, in particular saprophytic fungi, are often ignored during inventory of biodiversity in National Park Area. Saprophytic fungi is a fungus obtain nutrients by decomposing dead organisms or other organic material and act as decomposers in the ecosystem. Saprophytic fungi can be found grow on dead organic matter contained in the environment such as soil, wood, and litter. The diversity of Macroscopic saprophytic fungi from Ujung Kulon Natinal Park is reported here. Fungal identification was done by using variety of macroscopic characters. This study determined eight species that classified into six genus of saprophytic fungi, namely : Collybia, Crepidotus, Hygrocybe, Lepiota, Marasmius, and Mycena. By knowing diversity of saprophytic fungi, it is expected to add information about biodiversity as a preparation towards the further development of the potential of existing biodiversity in Indonesia.
\end{abstract}

Key words: Biodiversity, Fungi, Saprophytic, Ujung Kulon National Park.

\section{PENDAHULUAN}

Informasi terkait keanekaragaman organisme merupakan aspek penting dalam upaya pelestarian biodiversitas di kawasan konservasi (Clarbough 2010). Jamur merupakan salah satu komponen penting dalam keberlangsungan ekosistem. Informasi mengenai keanekaragaman jamur dapat dijadikan acuan dalam menentukan kondisi ekologi dalam suatu kawasan (Dighton et al. 1992). Hawksworth (2001) melaporkan bahwa hingga saat ini baru diketahui baru 7\% saja dari estimasi 1,5 juta spesies fungi yang ada di dunia. Jamur saprofit asal tanah dan serasah mempunyai peranan penting sebagai dekomposer maupun tempat bagi sejumlah spesies serangga untuk meletakkan telur. Jamur saprofit adalah jamur yang mendapatkan nutrisi dengan menguraikan organisme mati atau bahan organik lainnya.

Taman Nasional Ujung Kulon (TNUK) merupakan daerah konservasi yang terletak di Provinsi Banten, Indonesia. Taman Nasional Ujung Kulon memiliki tipe vegetasi berupa hutan hujan tropis dataran rendah. Ekosistem yang terdapat pada kawasan TNUK antara lain berupa ekosistem hutan, pantai, dan mangrove dan memiliki tingkat keanekaragaman organisme yang cukup tinggi. Catatan mengenai keanekaragaman

*Penulis korespondensi : +62-82122733307

E-mail: ivanpermanaputra89@gmail.com jamur saprofit asal tanah dan serasah di wilayah Taman Nasional Ujung Kulon masih sangat sedikit, sehingga diperlukan inventarisasi data mengenai keragamannya.Tujuan dari penelitian ini adalah menyediakan informasi mengenai keanekaragaman jamur saprofit di Taman Nasional Ujung Kulon sebagai strategi pemanfaatan potensi biodiversitas di masa mendatang.

\section{BAHAN DAN METODE}

Pengambilan sampel. Pengambilan sampel dilakukan pada bulan Juli 2016 di lokasi Kalejetan dan Karang Ranjang (Gambar 1). Pengumpulan data jenis jamur dilakukan dengan metode ekplorasi yaitu jelajah secara acak terwakili mengacu kepada Puspitaningtyas (2007) dan Priyanti (2008). Sampel jamur yang telah dikoleksi, difoto dengan menggunakan kamera. Setelah itu, spesimen disimpan dalam kotak spesimen yang telah disediakan dan diberi label berupa nomor spesimen, kemudian dilakukan pencatatan data berupa jenis substrat tempat tumbuh jamur dan lokasi pengambilan spesimen. Jejak spora dibuat dengan meletakkan potongan tudung (cap) jamur pada karton berwarna putih dan hitam, kertas karton hitam berfungsi untuk melihat atau mengamati spora dengan warna terang dan kertas karton putih digunakan untuk mengamati warna spora yang gelap. Tudung (cap) jamur diletakkan 


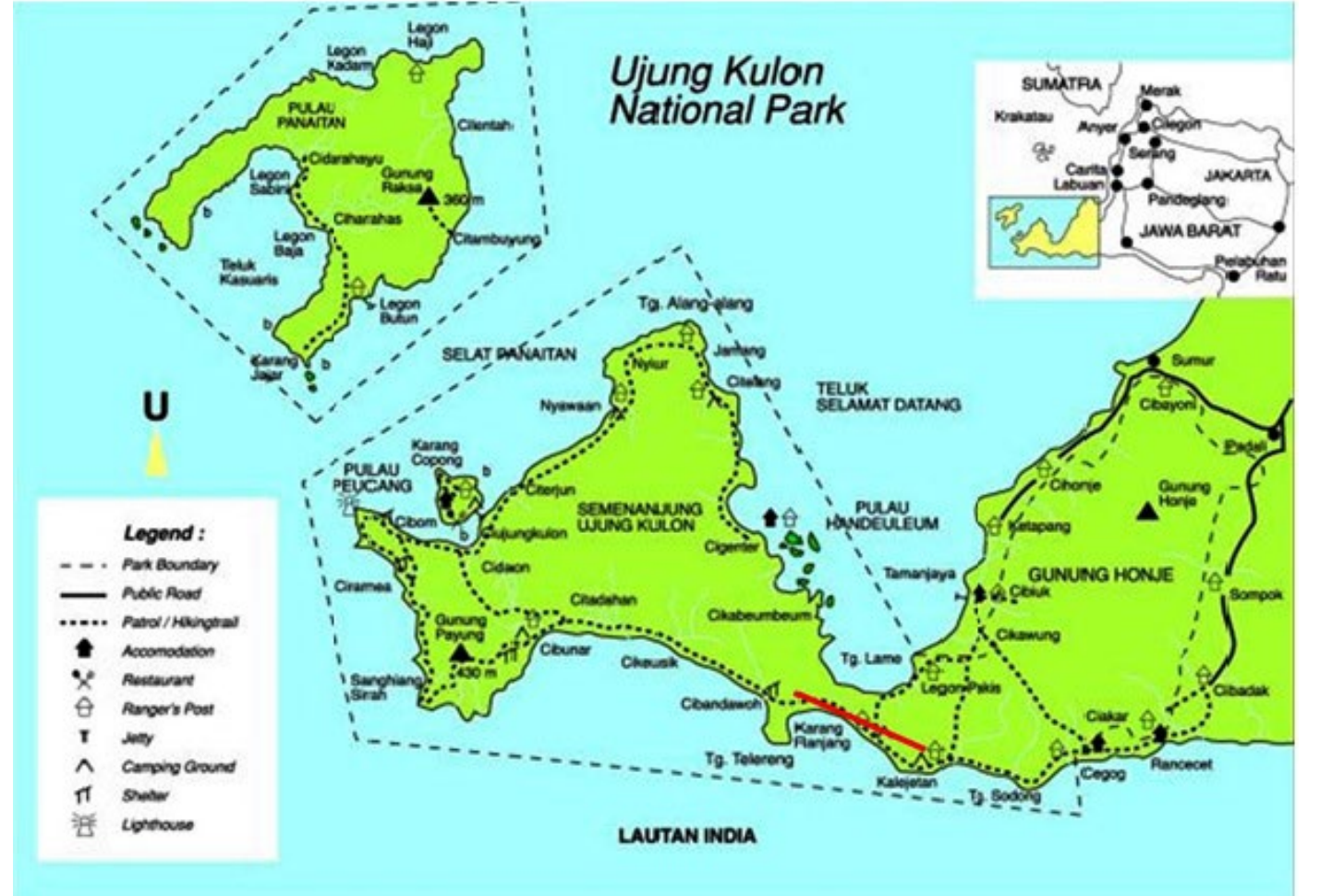

Gambar 1. Lokasi pengambilan sampel

diatas karton dan dibiarkan satu sampai dua hari, kemudian diangkat dari kertas karton dan jejak spora tersebut difoto menggunakan an jejak spora tersebut difoto menggunakan

Identifikasi jamur asal serasah dan tanah. Identifikasi jamur asal serasah dan tanah dilakukan dengan menggunakan karakter makroskopik. Pengamatan makroskopik dilakukan dengan menggunakan mikrosko stereo. Parameter Identifikasi makroskopik meliputi cara tumbuh, bentuk tubuh buah, warna cap, hygrophnous, warna tudung (cap) ketika tubuh buah muda dan tua, diameter $c a p$, bentuk atas dan bawah pada cap, permukaan cap, tepian cap, margin cap, tingkat kebasahan, tipe himenofor (lamela, poi, gigi) melipur cape himenofor (lamela pori, gigi) melipu cara menenpel pada stipe, panjang, jarak antar baris, margin, bentuk stipe, warna stipe (ketika muda dan tua), diameter dan panjang stipe, permukaan stipe, posisi penempela pada cap, tipe penempelan stipe pada substrat, penampang stipe, partial veil dan universal veil. Karakter lain yang diamati yaitu tekstur tubuh buah, bau dan rasa, serta edibel atau non edibel. Spesimen yang telah diambil diidentifikasi dengan menggunakan beberapa acuan identifikasi diantaranya Largent(1973), Lincoff(1981), Arora (1986), McKnight dan Vera (1998).

Tabel 1. Jamur asal serasah dan tanah di TNUK

\begin{tabular}{clllll}
\hline No. & Species & Genus & Family & Order & Phylum \\
\hline 1 & Collybia sp. & Collybia & Agaricaceae & Agaricales & Basidiomycota \\
2 & Crepidotus sp. 1 & Crepidotus & Crepidotaceae & Agaricales & Basidiomycota \\
3 & Crepidotus sp. 2 & Crepidotus & Crepidotaceae & Agaricales & Basidiomycota \\
4 & Hygrocybe sp. & Hygrocybe & Hygrophoraceae & Agaricales & Basidiomycota \\
5 & Lepiota sp. & Lepiota & Agaricaceae & Agaricales & Basidiomycota \\
6 & Marasmius sp. 1 & Marasmius & Marasmiaceae & Agaricales & Basidiomycota \\
7 & Marasmius sp. 2 & Marasmius & Marasmiaceae & Agaricales & Basidiomycota \\
8 & Mycena sp. & Mycena & Mycenaceae & Agaricales & Basidiomycota \\
& & & &
\end{tabular}

Collibya sp. Collybia tumbuh secara berkelompok tetapi jarak antar tubuh buah berjauhan (scattered) pada substrat berupa serasah. Tudung (cap) berwarna pada substrat berupa serasah. Tudung ( cap) berwarna pada bagian tengah (Gambar 2.a), terjadi sedikit perubahan warna tudung setelah beberapa waktu menjadi cokelat tua (hygrophnous) namun tidak ada perbedaan warna yang signifikan antara tubuh buah muda dan tua. Tudung berdiameter $15 \mathrm{~mm}$. Bagian atas berbentuk lonceng (bell shape) ketika muda dan berbentuk cembung hingga datar ketika tua, bagian bawah tudung berbentuk bulat (round) (Gambar 2 b) rerdich tung bergerigi besar (crenate)(Gar 2, tepian (c) 2.c), dan margin tud (Gambar 2.d).Colybiameniliki tipe himenofor berupa lamela yang cara menempelnya pada stipe dengan jarak yang sempit (adnexed), panjang lamela $6 \mathrm{~mm}$, jarak antar baris rapat (crowded) dengan margin bergerigi kecil(serrulate) (Gambar 2.e). Tangkai (stipe) berbentuk silindris, menempel di tengah tudung (central), dan berongga (hollow)(Gambar 2.f). Diameter stipe $1 \mathrm{~mm}$ dan panjang 20-40 mm. Permukaan stipe halus, stipe menempel pada substrat dengan tipe penempelan rhizoid (Gambar 2.f). Tekstur tubuh buah jamur ini lunak berdaging tidak berbau.

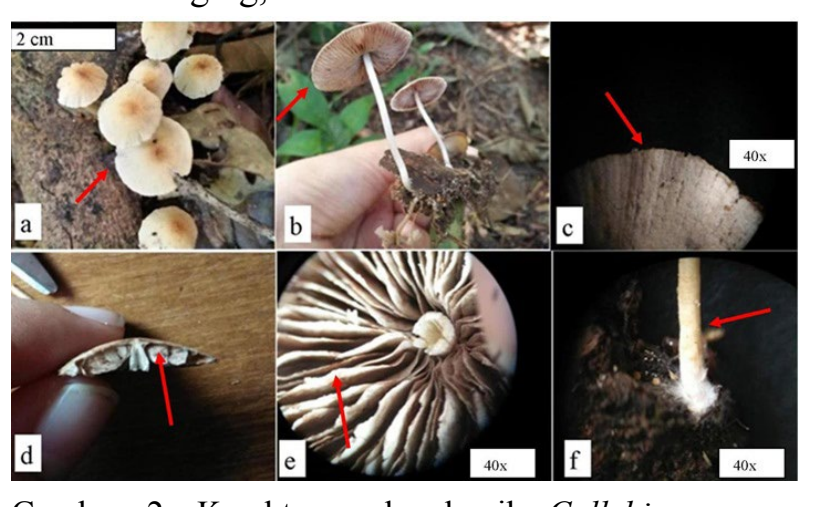

Gambar 2. Karakter makroskopik Collybia sp.yang dikoleksi dari TNUK. a. bentuk atas tudung; b. bentuk bawah tudung, c. bentuk tepian tudung; d.margin tudung; e. lamela; f. Stipe.
Crepidotus sp.

. Crepidotus sp. 1

Crepidotus sp.1. Tumbuh secara berkelompok pada serasah, tudung berwarna putih (Gambar a), terdapat perubahan warna tudung (hygrophnous) dari warna putih menjadi kuning. Tudung berdiameter $15 \mathrm{~mm}$ dengan bagian tas berbentuk datar (flat) dan jika dilihat da bawah berbentuk ginjal (dimidate) (Gambar 3.b). Permukaan tudung ( $c a p$ ) halus dengan (epian bergelombang (undulate) (Gambar c) dan margin lurus (decurve). Crepidotus emiliki tipe himenofor berupa lamela cara mada stipe dengan jarak yang (c) (distant) dengan margin halus (Gambar 3.d) don . 8 mipe berbentuk silindris, enang 8 mipe berbentuk silndris, ke le $\mathrm{mm}$ dan panjang $3 \mathrm{~mm}$, permukaan halus, menempel pada tudung secara terminal dengan Cenampang berongga (hollow). Jejak spora Crepidotus menunjukkan spora berwarna putih (Gambar 3.e). Tubuh buah bertekstur lunak dan tidak berbau.

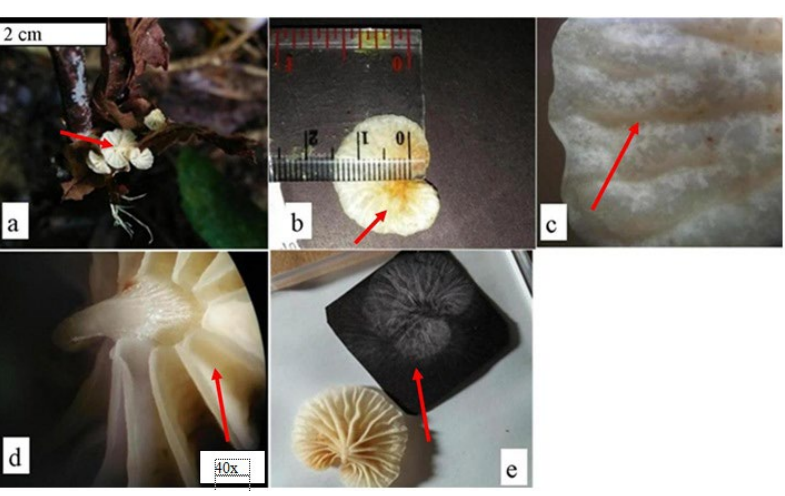

Gambar 3. Karakter Makroskopik Crepidotus sp. 1 yang dikoleksi dari TNUK: a. cara hidup; b. bentuk tudung; c. karakter permukaan tudung; $d$. jarak antar lamela; e. jejak spora. 
b). Crepidotus sp.2.

Crepidotus sp.2. Tumbuh baik pada serasah secara berkelompok dengan jarak antar tubuh buah sangat dekat (caespitose), tudung berwarn putih (Gambar 4.a), berdiameter $12 \mathrm{~mm}$, dan terjadi perubahan warna setelah beberapa waktu dari warna putih menjadi kecoklatan. Bagian atas berbentuk lonceng (bell shape) (Gambar 4.b) dan jika dilihat dari bawah berbentuk ginja (dimidate) (Gambar 4.a), permukaan memilik rambut halus (felty-hairy) dengan tepian rat (entire) (Gambar 4.c) dengan margin mirin paralel sedikit ke bawah (plane), serta memiliki ingkat kebasahan kategori lembab. Crepidotus memiliki tipe himenofor berupa lamela yan menempel pada stipe dengan jarak yang sempit (adnexed), jarak antar baris kurang rapat denga margin bergerigi kecil (serrulate)(Gambar 4.d) dan panjang lamela $14 \mathrm{~mm}$. Crepidotus menempel pada substrat dengan stipe semu ata pseudostipe (substipitate) (Gambar 4.e). Tubuh puah bertekstur lunak dan yang khusus.

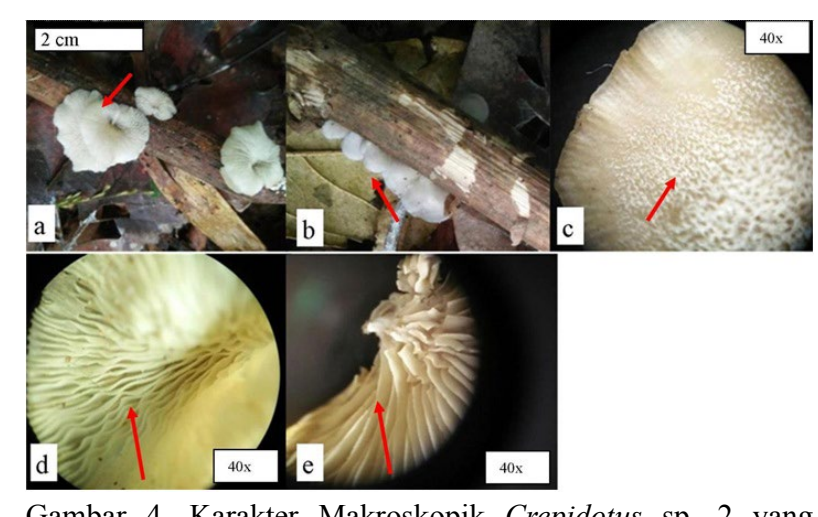

dikoleksi dari TNUK: a bentuk atas tudung; bentuk bawah tudung; c. permukaan tudung; jarak antar lamela; e. margin lamela

Hygrocybe sp.

Hygrocybe tumbuh pada substrat berupa tana yang tumbuh secara soliter, tudung berwarna put hingga jingga tanpa terjadi perubahan warna setela beberapa waktu (Gambar 5.a), tubuh buah ketika mud berwarna putih hingga kuning muda dan ketika tua berwarna putih hingga kuning pekat. Tudung berbentuk kerucut (conical) (Gambar 5.a) dan jika dilihat da (Gambar 5.b) dengan . 26 m. Permukan (Gang halus, depian . c) deng, tepian (Gergelonbang (undulate) (Ganbar s.c) dengan margin miring pararel sedikit ke bawah (plane) (Gambar 5.d). Hygrocybe memiliki tipe himenofor berupa lamela, ca menempelnya bebas pada stipe, jarak antar barisny kurang rapat (medium) dengan margin berombak tida beraturan (wavy-eroded) (Gambar 5.e) dan panjang lamela $15 \mathrm{~mm}$. Stipe berbentuk clavate yaitu bagian dasar stipe membesar, berwarna putih dengan diameter $6 \mathrm{~mm}$ dan panjang $70 \mathrm{~mm}$. Stipe memiliki permukaa seperti garis-garis jalur (tread-like), posisi penempela pada tudung yaitu central. Stipe memiliki penampan dengan rongga dibagian tengah (hollow) (Gamber 5.f). Tubuh buah memilik memiliki tekstur lunak berdaging dan tidak berbau.

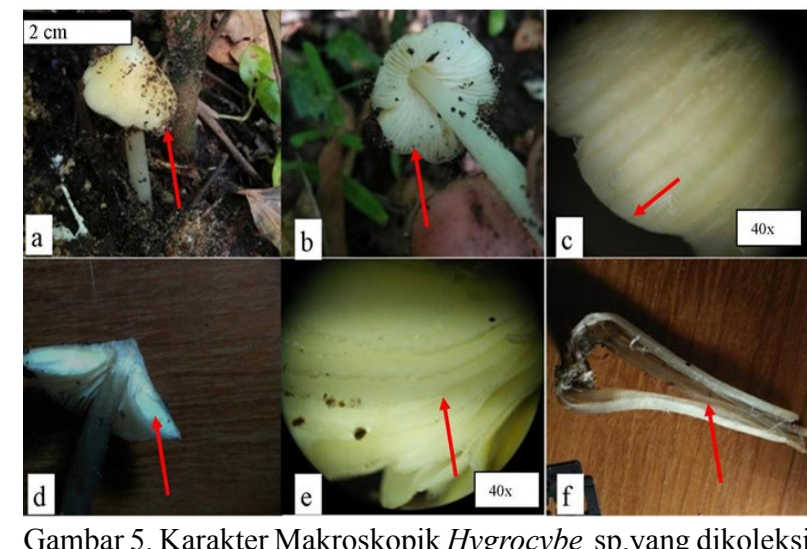

ambar 5. Karakter Makroskopik Hygrocybe sp.yang dikoleks dari TNUK: a. bentuk tudung; $b$. bentuk bawa e. margin lamela; f. penampang stipe.

Lepiota sp. tumbuh secara soliter di lantai hutan. Tudung berwarna putih hingga kuning kecoklatan tanpa terjadi perubahan warna setelah beberapa waktu (hygrophnous) (Gambar 6.a), tudung berdiamete $20 \mathrm{~mm}-40 \mathrm{~mm}$ dengan tudung berbentuk cembung (convex) sampi dat (fat) dan jik dilibung bawah berbentuk bulat ( perubahan bentuk tudung (cap) ketika fase muda da tua. Permukaan tudung berupa sisik (scaly), tepian bergerigi besar (crenate) (Gambar 6.c), memilik margin melengkung atau miring keatas (uplifted), dan memiliki tingkat kebasahan yang lembab. Lepiota memiliki tipe penempelan lamela pada stipe dengan jarak yang sempit namun sedikit runcing pada daerah penempelan (emarginated), sedikit mirip dengan adnexed, jarak antar baris rapat (crowled) da margin rata (entire) (Gambar 6.d). Stipe med) dan dari bagian pangkal ke ujung (tapered from base apex), wa ketika muda lebih pekat sedangkan ketika tua warna mulai puder, diamer supe 6 m panjang 22-65 mm dan , dipe $6 \mathrm{~mm}$ bena benang-benang fibril (fibrillouse). Stipe menempe di tengah tudung (central) dengan penampang stipe berongga (hollow). Partial veil berupa cincin atau annulus yang terletak dibagian atas stipe (superior) (Gambar 6.e), sedangkan universal veil terdapat pada tudung (cap) berupa sisik (scaly). Karakter mikroskopik spora berwarna jingog berbentuk ovoid den ornen permukan halus. Lepiota ovoid

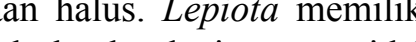
tekstur tubuh buah lunak dan berdaging serta tidak
memiliki bau yang khusus.

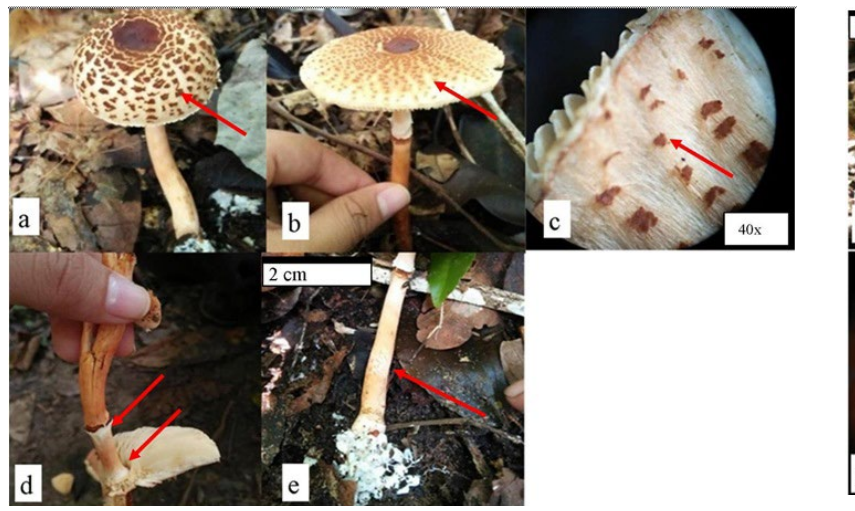

Gambar 6. Karakter Makroskopik Lepiota sp.yang dikoleksi dari TNUK : a. bentuk tudung tubuh buah muda; b. bentuk tudung tubuh buah dewasa; $c$. sisik pada permukaan tudung; d. cincin (atas), cara penempela
lamela pada stipe (bawah); e. stip.

Marasmius sp.

Marasmius sp. 1. tumbuh di serasah secara berkelompok (gregarious) denganjarakyang berdekatan (Gambar 7.a). Tubuh buah memiliki tekstur lunak. Marasmius memiliki tudung yang berwarna jingga kecokelatan tanpa terjadi perubahan warna setelah beberapa waktu (hygrophnous). Tubuh buah ketika muda berwarna jingga tua dan warna memudar ketika tua, tudung (cap) berbentuk lonceng (bell shape) hingga datar (flat) (Gambar 7.b), dan berdiameter 18 $\mathrm{mm}$. Apabila dilihat dari bawah bentuk tudung bulat (round) (Gambar 7.c). Tepi tudung (cap) memiliki ekstur seperti bubuk (powdery), bagian atas halus (smooth), tepian bergelombang (undulate) (Gambar 7.d), dan margin miring paralel sedikit ke bawah (plane). Marasmius memiliki bentuk himenofor berupa lamela yang menempel pada stipe dengan jarak sempit namun sedikit runcing pada daerah penempelan (emarginated), ( stipe silindris, warna pada saat tua dan muda sama yaitu jingga kecokelatan. Diameter stipe $1 \mathrm{~mm}$ dan panjang $35 \mathrm{~mm}$ dengan permukaan halus. Posisi penempelan stipe di bagian tengah tudung (central), penampang stipe berongga (hollow), dan menempel pada substrat dengan tipe rhizoid (Gambar 7.f).

c). Marasmius sp. 2

Marasmius sp.2 tumbuh berkelompok pada serasah dengan jarak antar tubuh buah berdekatan (gregarious). Tudung (cap) berwarna putih, tidak terdapat perubahan warna setelah beberapa waktu (hygrophnous), warna ketika tubuh buah muda dan tua tetap berwarna putih, bagian atas berbentuk lonceng (bell shape), dan jika dilihat dari bawah berbentuk bulat (round) (Gambar 8.a). Diameter tudung (cap) $5 \mathrm{~mm}$, tekstur permukaan halus dengan tepian rata (entire) (Gambar 8.b). Margin miring paralel sedikit ke bawah (plane) dan tingkat kebasahan yang lembab.

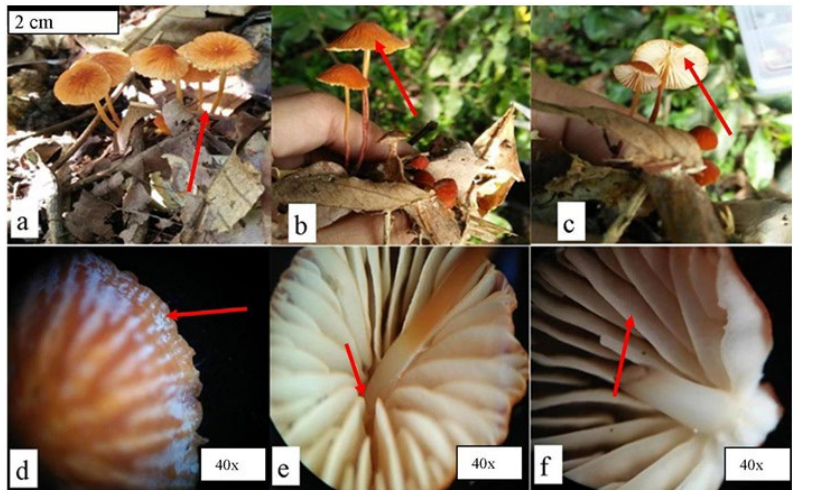

Gambar 7. Karakter Makroskopik Marasmius sp. 1 yang dikoleksi dari TNUK: a.cara tumbuh; b.bentuk tudung; e. margin lamela; f. jarak antar lamela.

Marasmius memiliki lamelayang menempel padastipe engan jarak sempit (adnexed), jarak antar baris rapa (crowded), margin halus (Gambar 8.c), dan panjang amela 6-8 mm. Stipe berbentuk silindris, berdiameter $\mathrm{mm}$, panjang $51,5 \mathrm{~mm}$, dan tekstur permukaan berupa benang-benang fibril (fibrillous) (Gambar 8.d). Stipe menempel pada substrat dengan tipe rhizoid, serta memilikipenampang berongga (hollow) (Gambar 8 e). iliki tubuh buah dengan tekst dan tidak terdapat bau yang khusus.

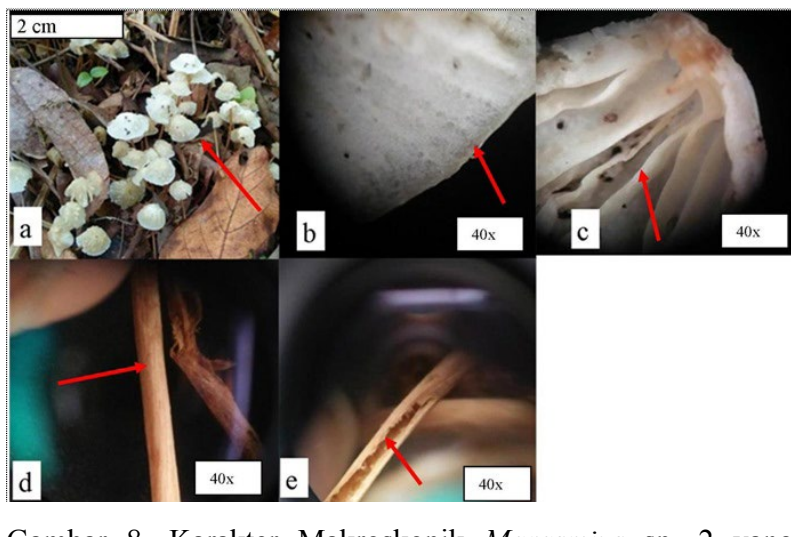

Gambar 8. Karakter Makroskopik Marasmius sp. 2 yang dikoleksi dari TNUK: a. cara tumbuh; b. tepian tudung; c. margin lamela; d. tekstur stipe; e.
penampang stipe penampang stipe

Mycena sp. yang dikeloksi dari TNUK tumbuh pad substrat serasah ranting secara berkelompok denga jarak antar tubuh buah berdekatan (gregarious). Mycena memiliki tudung ( $c a p$ ) berwarna jingga kecokelatan (Gambar 9.a), terjadi perubahan warna setelah beberapa waktu (hygrophnous), dan warna ketika tubuh buah muda dan tua berbeda. Warna ketika tubuh buah mud yaitu kekuningan dan tubuh buah tua berwarna cokelat muda. Tudung (cap) berdiameter $12 \mathrm{~mm}$ dengan bagian atas berbentuk cembung (convex) dan apabila diliha dari bawah berbentuk bulat (round) (Gambar 9.b). 
Permukaan tudung (cap) halus dengan tepian rata Jamur membutuhkan air untuk mengambil nutris

(entire) dan margin sedikit melengkung (incurved) melalui dinding dan membran sel serta untuk (Gambar 9.c). Mycena memiliki tipe himenofo berupa lamela, menempel pada stipe dengan jarak yang sempit (adnexed), jarak antar baris kurang ( an panjing lamela $6 \mathrm{~mm}$. Mycena memilk

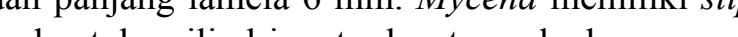
(tipentuk silindris, terdapat perbedaan warn stipe ketika muda berwarna putih dan ketika tu berwarna kuning hingga cokelat (Gambar 9.e). Stipe berdiameter $1 \mathrm{~mm}$ dan panjang $28 \mathrm{~mm}$, permukaannya halus, posisi penempelan stipe pada tudung di bagian tengah (central), dan penampang stipe berongga (hollow). Mycena tidak memiliki partial veil dan universal veil. Mycena memiliki ekstur tubuh buah lunak, tidak memiliki bau den rasa yang khusus dan belum terdapat informasi mengenai penggunaan jamur tersebut sebagai bahan pangan di kawasan TNUK.

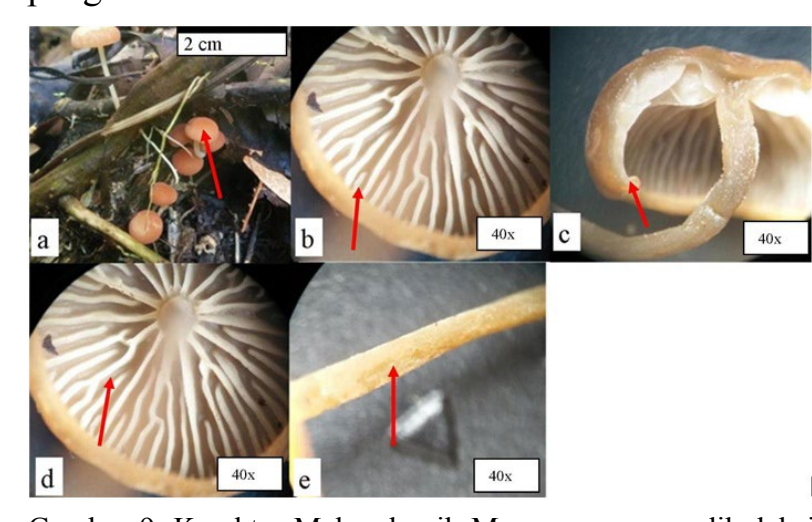

Gambar 9. Karakter Makroskopik Mycena sp. yang dikolek dari TNUK: a. bentuk atas tudung; b. bentuk baw e.stip

PEMBAHASAN

Eksplorasi keragaman jamur di kawasan Taman Nasional perlu ditingkatkan sebagai upaya awa inventarisasi dan pengelolaan potensi sumberdaya hayati yang ada.Jamur yang dikoleksi dari TNUK humbuh di bawah kanopi hutan dan doer yang

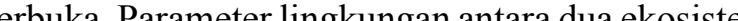
rsebut sanget bet terutana pada intesitas cahay da calo kanopi hutan lebih rapat menyebabkan lingkunganny lebih teduh dengan kelembapan relatif lebih tingg. Namun demikian, pengaruh kedua faktor ini pad keanekaragaman jamur asal tanah dan serasah belum diketahui. Thomas et al. (1988) menyatakan bahwa kecepatan angin mempengaruhi kelembapan relatif pada suatu ekosistem dan mempengaruh erkembangan hifa cendawan. Kelembapan pada suatu habitat jamur mempengaruhi ketersedian komponen abiotik lainnya. mengeluarkan enzim ekstraseluler. Jamur juga (a)

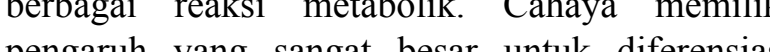
jamur, berfungsi menggerakkan produksi struktu spora aseksual dan seksual pada beberapa jamur Contohnya pada jamur payung dan beberapa tubuh buah Basidiomycota yang dibentuk sebagai respon cahaya (Deacon 2006) dan serasah berhasil dikeloksi dari TNUK. Genus Collybia dikenal sebagai jamur yang memiliki kemampuan mendekomposisi serasah dengan sangat baik (Osono dan Takeda 2006. Steffen et al. 2002) sehing a merupan sal sal komp ekosistem yang penting. Beberapa lapora penelitian menunjukkan bahwa genus ini telah banyak dimanfaatkan sebagai pangan fungsiona (Lim dan Yun 2006 ). Eksplorasi dan penelitian mengenai Collybia di Indonesia sendiri masih sangat terbatas dan belum ditemukan informasi mengenai penggunaan jamur ini sebagai bahan pangan khususnya di kawasan TNUK.

Genus kedua yang dikoleksi dari TNUK adalah Crepidotus. Semua jenis Crepidotus diketahui berperan sebagai dekomposer yang baik. Jamur berupa tunggul, kayu, ranting dan jarangpada lumut atau herba. Crepidotus yang dikoleksi dari TNUK merupakan dekomposer yang ditemukan pada berbagai macam tipe serasah dan kayu. Sebagian besar spesies Crepidotus memiliki tudung yang menempel secara lateral dengan tudung berbentuk ginjal atau semi-bundar (Gungor 2014). Tipe perkembangan tubuh buah jenis jamur ini adala gymnocarpic atau hemiangiocarpic (Aime et al. 2005). Kedua spesies Crepidotus yang diamati di TNUK memiliki perkembangan gym diarpic Genus ketiga yang berhasil dikoleksi dari TNUK adalah Hygrocybe. Genus ini memiliki tudung yang khas dengan warna cerah dan memiliki permukaa mengilap karena adanya lapisan permukaan yang bergelatin dan berbentuk kerucut (conical). Karakter ini sesuai dengan deskripsi Griffith et al. (2002) dan Chong et al. (2014) yang melaporkan bahwa warna tudung jamur genus ini berwarna cerah dan terjadi perubahan warna dari kuning cerah menjadi jingga sampai hitam ketika dewasa.

Genus keempat yang dikoleksi adalah Lepiota. Lepiota tumbuh secara soliter di lantai hutan dan memiliki stipe lebih panjang dari lebar tudung (cap)
Sebanyak 6 genus jamur saprofit asal tanah 2002) sehingga merupakan sal samponen tumbuh pada serasah daun dan ranting. Crepidotus
Lepiota yang diamati di TNUK memiliki lamela yang menempel pada stipe dengan jarak yang sempit dan runcing di bagian penempelannya (emarginate).Sysouphanthong et al. (2011) (elo yang memiliki keraganan spesies yan tingesar daerah tropis dan subtropis, sebagian besar jamur ni terdistribusi di Asia. Kebanyakan spesies Lepiota dinyatakan beracun karena mengandung amatoxin (cyclopeptides) yang menyebabkan kerusakan hati dan pankreas, namun terdapat beberapa spesies yang dapat dimakan dan dijadikan bahan obat-obatan, diantaranya adalah MacroLepiota, L. aspera, $L$. grassei, L. henningsii, dan L. magnispora (Boa 2004). Hingga saat ini belum terdapat informasi mengenai penggunaan genus ini sebagai bahan pangan par plan merupakan genus paling banyak ditemukan di kedua lokasi TNUK. Sebanyak dua spesies dikoleksi dari kawasan TNUK. Marasmius memiliki persebaran yang luas di dunia dengan jumlah lebih dari 600 spesies. Hutan tropis umumnya dikolonisasi oleh Marasmius yang berperan membusukkan daun dan ranting jatuh bahkan daun tua yang masih terdapat di kanopi. Beberapa spesies membentuk basidioma secara langsung pada rhizomorf yang tebal pada daun atau pada dahan mati. Spesies dari penus Marasmius berperan penting dalam dari genus Maram pala Kendekome Marisisus meniliki korelasi Keragaman Marasmius memiliki korelasi yang kuat dengan keragaman flora lokal, khususnya pada habitat tropis (Shay 2016). Desjardin et al. (2000) mendeskripsikan 37 spesies Marasmius dari Jawa dan Bali, 12 diantaranya merupakan spesies baru. Peluang untuk mendapatkan jenis Marasmius lain di Indonesia sangat besar mengingat kawasan hutan tropis yang luas dan eksplorasi keragaman jamur belum terinventarisasi dengan maksimal. Genus Terakhir yang berhasil dikoleksi adalah Mycena.

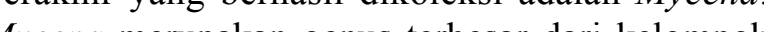
Agaricales. Mycena memiliki penyebaran yang garicales. Mycena memiliki penyebaran yang sangat luas dan memiliki fungsi yang penting sebagai dekomposer untuk menjaga ekosistem agar tetap memiliki persediaan nutrien yang esensial bagi tumbuhan. Tyler (1991) melaporkan bahwa beberapa spesies diketahui mampu mendekomposisi lignin, selulosa, dan hemiselulosa.

\section{UCAPAN TERIMA KASIH}

Penulis mengucapkan terimakasih kepada Kentaro Hosaka PhD (Tsukuba Botanical Garden).
DAFTAR PUSTAKA

Arora D. 1986. Mushrooms Demystified. USA: Teen Speed Pres. MC, Vilgalys R, Miller OK. 2005. The crepidotacea the genera and revision of the family based ax momy of evidence. American Journal of Botany. 92(1): 74-82.

Ba E. 2004. Wild Edible Fungi A Global Overview of Their Use and Importance to People Rome (IT): FAO.

hong EL, Sia CM, Khoo HE, Chang SK, Yim H. 2014 Antioxidative properties of an extract of hygrocybe conic a wild edible mushroom. Mal J Nutr. 20(1): 101-111.

brough ML. 2010. Ujung Kulon National Park Handbook Ujung K

Decon JW. 2006. Fungal Biology 4th Edition. British (UK): Blackwell publishing Ltd

DesjardinDE, RetnowatiA, HorakE. 2000. Agaricales of 2.Apreliminary monograph of Marasmius from Java and Bali. Sydowia. 52(2):92-194.

Dighton J, White J, Oudemans P. 1992. The Fungal Community Its Organization and Role inthe Ecosystem, Second Edition.

Amerika (US). CRC Press.
of waxcap (Hygrocybes sp.)f fungi. 2002 . Ecot.J. Scotogy and diversity 54 (1): 7-22. gor H dan Solak MH. 2014. New crepidotus (Fr) staud record for Turkish mycota. Biological Diversity and Conversation. 7(2): 127-128.

wksworth DL. 2001. The magnitude of fungal diversity : the 1.5 million speciesestimate revisited. Mycol.R

argent DL. 1973. How to Identify Mushroom to Genus

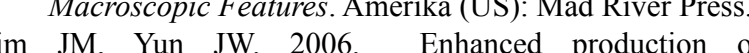
exopolysaccharides by supplementationof toluene in submerged culture of an edible mushroom Collybia maculata TG-1. Process Biochemistry 41:1620-1626.

non \& Schuster's Guide to Mushroo (Nature Guide Series). Amerika (US): Touchstone.

McKnight K, Vera M.1998.A Field Guide to Mushrooms: North . and Betula leaf litter. Mycologia 98(2): 172-279.

iiyanti. 2008. Tanaman monokotil di Kampus I dan II UIN SyarifHidayatullah Jakarta. Al-Kauniyah Jurnal Biolog 2(1):29-36.

uspitaningtyas DM. 2007. Orchid Inventory and the Host in Meru Betiri National Park-East Java. Biodiversitas 8(3)

JE. 2016. Biodiversity and phylogeny of marasmius Francisco Stare

Hen KT, Hatakka A, Hofrichter M. 2002. Degradation of
Humic Acids by the Litter-Decomposing Basidiomycet Collybia dryophila. App. Env. Micro 68(7) : 3442-3448.

Sysouphanthong P, Hyde KD, Chukeatirote $\mathrm{E}$ dan Vellinga $\mathrm{EC}$. 2011. A review of genus Lepiota and its distribution in Asi Current Research in Environmental \& Applied Mycolog.

omas CS, Marios JJ, English JT. 1988. The effect of win of aerial mycelium and conidia of Botrytis cinerea on grape. Phytopathology 78:260-265

Tyler G. 1991. Ecology of the genus Mycena in beech (Fagus sylvatica), oak (Quercus robur) and hornbean Carpinusbenlus) forest of Sweden. J. Bot. 11: 111-12 